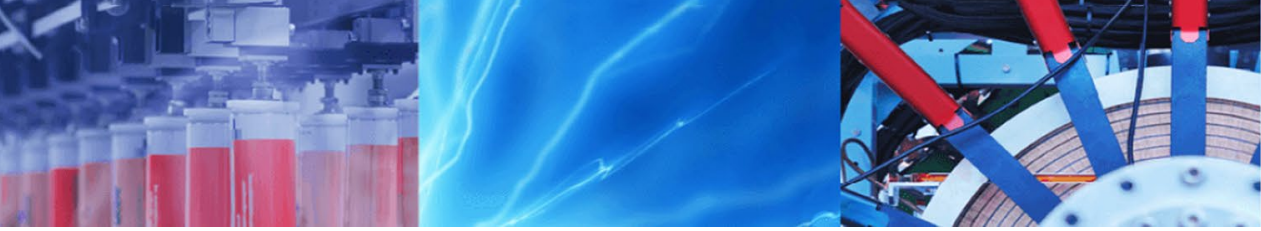

Research Article

\title{
Metathesized castor oil acylated derivatives: lubricants base stocks with low pour points and superior anti-wear properties
}

\author{
Vyshnavi Yelchuri $^{1}$ (D) . Thirupathi Azmeera ${ }^{1}$ (D) M. S. L. Karuna ${ }^{1}$ (D)
}

(c) Springer Nature Switzerland AG 2019

\begin{abstract}
Castor (Ricinus communis) oil containing ricinoleic acid $89 \%$ was self-metathesized in the presence of Grubbs' second generation catalyst $(0.025 \mathrm{mmol})$, followed by epoxidation and insitu hydroxylation using Prilezhaev dihydroxylation method to obtain hydroxylated derivatives in $93 \%$ yields. MALDI study has shown that the metathesized products comprised of a mixture of monomer, dimer and trimer metathesized products. The hydroxylated derivatives were acylated using acetic, propionic, butyric and hexanoic anhydrides in $85-90 \%$ yields. The acylated base stocks being highly branched and of high molecular weights exhibited very low pour points $\left(-30\right.$ to $\left.-40^{\circ} \mathrm{C}\right)$ and broad viscosity ranges $45.5 \mathrm{cSt}$ to $60.0 \mathrm{cSt}$ at $40^{\circ} \mathrm{C}$, high viscosity indices (165-191), excellent anti-wear properties $(0.52-0.69 \mathrm{~mm})$, good thermal and oxidative stabilities along with high load carrying capacities (165-184 kg) suitable for multi-range industrial applications. These base stocks can be used with the addition of minimum additives during the formulation.
\end{abstract}

Keywords Castor oil · Lubricants · Oxidation stability · Antioxidants · Metathesis

\section{Introduction}

Lubricants play a critical role in increasing the efficiency of manufacturing and transportation systems by reducing the energy consumption and release of green house gases (GHG). However, lubricants can also be a source of several toxic materials due to accidental or intentional leakage to the environment. Today over $95 \%$ of the lubricants are petroleum based and about $50 \%$ of the lubricants end up in total loss applications, volatility, spills or major accidents [1-4]. In this context, plant based oils have gained importance during the last couple of years. The triglyceride structure of plant oils makes them excellent lubricants. They exhibit excellent biodegradability (95\%), reduced environmental pollution [5] compatible with additives, low production costs [6] large possibilities of production, low toxicity, high flash points, low volatility, high viscosity indices and excellent tribological performances. However, they posses few disadvantages like low thermo oxidative, hydrolytic stabilities and low temperature properties [7]. Low temperature properties are important for lubricant pump abilities, filterability, fluidity as well as cold cracking and start up. These drawbacks can be overcome by chemically modifying the triglyceride structure. Trans etherification of alkene groups to other stable functional groups can improve the oxidation stability, while reducing structural information of the oil by attaching alkyl side chains can improve the low-temperature performance.

Introducing branching around the polar group of a lubricant protects the molecule from physical and chemical interactions due to stearic hinderance. Some of such modifications include epoxide ring opened products [8, 9] and polyol esters [10]. These inhibit the stacking of molecules and crystallization leading to microcrystalline

Electronic supplementary material The online version of this article (https://doi.org/10.1007/s42452-019-1263-0) contains supplementary material, which is available to authorized users.

M. S. L. Karuna, mslkaruna@gmail.com; karuna@iict.res.in | ${ }^{1}$ Centre for Lipid Science and Technology, CSIR-Indian Institute of Chemical Technology, Hyderabad 500007, India. 
structures at very low temperatures [11]. In addition branching also leads to better thermal, oxidative and hydrolytic stabilities $[12,13]$. Molecular branching and high viscosity is beneficial in lubrication involving high contact loads or extreme pressure [14] in case of biolubricants compared to mineral oil based. The reason for high load carrying capacity is the stabilization of the tribofilm from breaking apart [15].

Both viscosity and branching are thus most important parameters to develop an ideal biolubricant base stock. One of the integrated methods used for making such modifications for applications into synthetic hydrocarbon fluids, plasticizers and polar synthetic lubricant base stocks from a renewable feed stock is metathesis. Metathesis of natural oils or its derivatives in the presence of an efficient amount of metathesis catalysts can form linear alpha olefin, internal olefins and reduced chain length triglycerides [16]. The reduced chain length triglycerides are converted into polar synthetic lubricants base stocks or may be epoxidized followed by derivatizing the epoxide as required for different industrial applications.

Branching of alkyl chain of vegetable oils is one of the modifications used for the production of lubricant additives for fuel and lubricant rolling and drawing oils and also as solvents for painting inks [17-29]. Branching fatty acids have advantages like low melting point, distinctly reduced pour points in biodiesel and lubricants, formulation, good oxidation stability due to reduced $\mathrm{C}-\mathrm{C}$ double bonds. Branching is generally carried out using different synthetic methods like epoxidation or dihydroxylation of double bonds in the triglycerides followed by acylation. Selection of new materials and its chemistry play a vital role in the economics and performance of the lubricant produced. In this context, castor oil (Ricinus communis) containing about $87-90 \%$, mono unsaturated hydroxyl fatty acid widely grown crop in India, 9-10 lakh MT (2015), a major source for a number of oleochemicals was selected as the raw material. Castor rich in monounsaturated hydroxyl fatty acid has been exploited for the preparation of a number of lubricant base stocks [18, 22, 30,31]. However, no single modification resulted in lubricant base stocks with very low temperature properties associated with high viscosities, superior anti-wear and high load carrying capacities. In this context, olefin metathesis of castor oil can help in generating molecules with unusual chain lengths and high branching.

Hence, in the present study castor oil was subjected to self-metathesis to prepare highly branched structures employing Grubbs' second generation catalyst. The concentration of the catalyst was varied from 0.1 to $0.5 \mathrm{~m} \mathrm{~mol}$ to study the effect of catalyst concentration on the product formation. The metathesized castor oil was epoxidised followed by in situ hydroxylation and acylation to develop metathesized castor acylated products. The products were evaluated for physico-chemical and lubricant properties.

\section{Experiment}

\subsection{Material}

Castor oil (BSS grade) obtained from M/s Ramcharan Industries Pvt. Ltd., Hyderabad, India, Tricyclohexylphosphine-[1,3-bis(2,4,6-trimethylphenyl)-4,5-dihydroimidazol2-ylidene] benzylidene ruthenium (IV) dichloride (Grubbs second generation catalyst) (II) was purchased from $\mathrm{M} / \mathrm{s}$ Sigma Aldrich Ltd. (Mumbai, India), DMAP, acetic anhydride, xylene, aluminum oxide active basic and sodium sulphate were purchased from M/s S.D. Fine chemicals Pvt. Ltd., (Mumbai, India). Propionic, butyric and hexanoic anhydrides were procured from M/s Sigma Aldrich Ltd. (Mumbai, India). Hexane and ethyl acetate were procured from Industrial Solvents and Chemicals Pvt. Ltd (Mumbai, India). All the solvents and reagents were of analytical grade and were used directly without any further purification.

\subsection{Methods}

\subsubsection{Spectral analysis}

Infrared spectra (FTIR) were obtained using a 1600 FT-IR BRUKER Spectrometer (Norwalk, CT). The spectra were recorded in a transmittance mode with a liquid film between $\mathrm{KBr}$ cells. Proton nuclear magnetic resonance $\left({ }^{1} \mathrm{H}\right.$ NMR) spectra were recorded on Avance $(300 \mathrm{MHz})$ equipment in $\mathrm{CDCl}_{3}$. Chemical shift values relative to TMS as internal standard are given as $\delta$ values in ppm. Carbon nuclear magnetic resonance $\left({ }^{13} \mathrm{C}\right.$ NMR) spectra were recorded in $\mathrm{CDCl}_{3}$ on a Varian $(75 \mathrm{MHz})$ spectrometer. MALDI-TOF/MS analysis of castor metathesized products was carried out using a Shimadzu Biotech Axima CFR Plus instrument equipped with an $\mathrm{N}_{2}$ laser $(337 \mathrm{~nm}, 3 \mathrm{~ns}$ pulse width, $20 \mathrm{~Hz}$ reprtition rate). Mass spectra were acquired in both the linear and reflector ion and a range of $\mathrm{m} / \mathrm{z}$ 300-2000 ranges was explored. The instrument was operated with an accelerating voltage of $20 \mathrm{kV}$. The matrix solution was prepared by dissolving $10 \mathrm{mg}$ crystalline a-cyano-4-hydroxycinnamic acid (CHCA) in $1 \mathrm{ml}$ of methanol containing $0.1 \%$ TFA. The sample was dissolved in chloroform at a concentration of $10 \mu \mathrm{l} / \mathrm{ml}$. An aliquot of the chloroform layer $(10 \mu \mathrm{l})$ was mixed with the matrix (1:1, $v / v)$, and $1 \mu \mathrm{l}$ of the resulting solution was deposited onto the sample plate and air dried. Typically, 196 laser pulses were acquired for each spectrum. To check the repeatability, samples were analyzed in triplicate. 
The Chromatograms and the Spectra along with the characterization are provided in the supporting information.

\subsubsection{Thermogravimetric analysis (TGA)}

TGA were carried out in a non-isothermal mode using a Mettler Toledo TGA instrument to get the decomposition pattern of the lubricant base-stocks. About $5 \mathrm{mg}$ of the sample was taken in an aluminium crucible and heated slowly up to $600{ }^{\circ} \mathrm{C}$ at a rate of $10^{\circ} \mathrm{C} / \mathrm{min}$ under nitrogen atmosphere. The TGA degradation onset temperature was obtained by extrapolating the horizontal base line and intercept of this line with tangents to the downward portion of the weight curve.

\subsubsection{Physico-chemical and lubricant properties}

The lubricant properties of acylated metathesized castor oil derivatives (base-stocks) was carried out using standard AOCS and ASTM methods.

2.2.3.1 Total acid value Acid value was determined by following the procedure as per the standard AOCS Cd $3 \mathrm{~d}-63$ method. About $2 \mathrm{~g}$ of the sample was dissolved in $50 \mathrm{~mL}$ of neutralized methanol. The resultant solution was titrated with $0.1 \mathrm{~N} \mathrm{KOH}$ solution using phenolphthalein as indicator. The acid value was calculated using the expression.

Acid value (AV)

$$
=\frac{(\mathrm{mL} \text { of alkali used for titration } \times \text { normality of alkali } \times 56.1)}{W t \text { of the sample }}
$$

2.2.3.2 Hydroxyl value Hydroxyl value is a measure of hydroxyl content. Hydroxyl value is defined as the number of milligrams of potassium hydroxide required to neutralize the amount of acetic acid capable of combining by acetylation with $1 \mathrm{~g}$ of sample. Hydroxyl value was determined by standard AOCS Cd 13-60 Official Method. A suitable quantity of sample was taken in $5 \mathrm{~mL}$ of pyridine/acetic anhydride (3:1, v/v) and the contents were refluxed on water bath for $1 \mathrm{~h}$. To this $10 \mathrm{~mL}$ of water and $25 \mathrm{~mL}$ neutralized $\mathrm{n}$-butanol were added, and heated 10 more minutes. The contents were titrated against standard $0.5 \mathrm{~N}$ of alcoholic potassium hydroxide solution. The end point was indicated by phenolphthalein. To correct for free acid, mix about $10 \mathrm{~g}$ of the sample, accurately weighed, with $10 \mathrm{ml}$ of pyridine (neutralized), add $1 \mathrm{ml}$ of phenolphthalein and titrate to a faint pink endpoint with $0.5 \mathrm{~N}$ ethanolic potassium hydroxide.

Hydroxyl value $=\left[56.1 \times \mathrm{N}\left(\mathrm{V}_{\mathrm{B}}-\mathrm{V}_{\text {acet }}\right)\right] / \mathrm{Wt}_{\text {acet }}+\mathrm{AV}$ where $\mathrm{V}_{\mathrm{B}}$ is $\mathrm{ml}$ of $\mathrm{KOH}$ solution required for the titration of blank; $\mathrm{V}_{\text {acet }}$ is $\mathrm{ml}$ of $\mathrm{KOH}$ solution required for the titration of acetylated sample; $\mathrm{Wt}_{\text {acet }}$ is the wt of the sample (in gm) used for acetylation; $\mathrm{N}$ is the normality of $\mathrm{KOH} ; 56.1$ is the molecular Wt of $\mathrm{KOH}$; $\mathrm{AV}$ is the acid value of the hydroxyl compound.

2.2.3.3 Oxirane value The oxirane oxygen content of sample was measured as per the standard AOCS Cd 9-57 official method. ${ }^{31 \mathrm{~b}}$ The oxirane value was calculated as follows

Oxirane oxygen $=\frac{\mathrm{mL} \text { of } \mathrm{HBr} \text { consumed } \times \mathrm{N} \text { of } \mathrm{HBr} \times 1.60}{\text { Wt of sample }(\mathrm{g})}$

2.2.3.4 Density The density of the products was determined using an Anton Paar DMA $4500 \mathrm{M}$ density meter at $15^{\circ} \mathrm{C}$ as per the ASTM method (ASTM, 2011). The measurements were carried out thrice and the results reported are an average of the three.

2.2.3.5 Kinematic viscosity and viscosity index (VI) Kinematic viscosity was measured using calibrated CannonFenske viscometer tubes in a Cannon Constant Temperature Viscosity Bath (Cannon Instrument Co., U.S.A.) at $40^{\circ} \mathrm{C}$ and $100^{\circ} \mathrm{C}$. Viscosity and viscosity index (VI) were calculated using ASTM D 445 (ASTM, 1998) and ASTM D 2270 (ASTM, 2002a) methods, respectively. Duplicate measurements were made and the average values are reported.

Kinematic Viscosity $(\mathrm{cSt})=$ Viscometer constant $(\mathrm{cSt} / \mathrm{s}) \times$ time $(\mathrm{s})$

2.2.3.6 Pour point The pour points of the products were determined according to the ASTM D 97 method (ASTM, 2005) with an accuracy of $\pm 3^{\circ} \mathrm{C}$ using the pour point test apparatus manufactured by Dott Scavini \& Co, Italy. The sample temperature was measured in $3^{\circ} \mathrm{C}$ increments at the top of the sample until it stopped pouring, and all the runs were carried out in duplicate.

2.2.3.7 Flash point The Flash points of the products were determined using the Tanaka Scientific Ltd., Japan, apparatus according to the ASTM D 93 method (ASTM, 2002b). Duplicate measurements were made and the average values are reported.

2.2.3.8 Copper corrosion The determination of corrosiveness of the products was done using the Koehler Inc., U.S.A. apparatus as per the ASTM D 130 method (ASTM, 2004). A polished $\mathrm{Cu}$ strip is immersed in $30 \mathrm{~mL}$ of the sample being tested at $100{ }^{\circ} \mathrm{C}$ for $3 \mathrm{~h}$. After $3 \mathrm{~h}$, the $\mathrm{Cu}$ strip is removed, washed with n-hexane, and the colour and tarnish level were assessed against the ASTM Copper Strip Corrosion Standard. 
2.2.3.9 Oxidative stability by rotating pressure vessel oxidation test (RPVOT) The oxidative stability of the products was measured using a Koehler Inc., U.S.A. Rotator Bomb Oxidation Test apparatus as per the ASTM D 2272 test method (ASTM, 2002a). The experiment was carried out at $150{ }^{\circ} \mathrm{C}$, with a Cu catalyst, $55.5 \mathrm{~g}$; sample, $50 \mathrm{~g}$ and water, $5 \mathrm{~mL}$. The vessel was sealed and charged with oxygen to 90 psi pressure. The test was completed once the pressure dropped more than 25 psi below the maximum pressure.

2.2.3.10 Weld load The weld load of the products was determined using the Four Ball Tester manufactured by Stanhope Seta, U.K. according to the ASTM IP 239 method (ASTM, 2002c). Out of four balls, three clean balls are placed in the ball cup securely and the fourth ball is placed into the upper ball chuck. The ball cup assembly is positioned centrally under the spindle in contact with the fourth ball. Then the series of loads are applied on the weight pan with an increment of $10 \mathrm{~kg}$ and the motor is started for a period of $1 \mathrm{~min}$. The load at which the balls are welded or fused together is taken as the weld load of the product.

2.2.3.11 Wear The wear of the products was determined using the Four Ball Tester manufactured by Stanhope Seta, U.K. as per the ASTM D 4172 method (ASTM, 2002d). The point contact interface is obtained by rotating a $12.7 \mathrm{~mm}$ diameter steel ball under load against three stationary steel balls immersed in the lubricant. To evaluate the antiwear characteristics of lubricants, the subsequent wear scar diameters on the balls is measured.

\subsection{Typical procedure for the self-metathesis of castor oil}

Castor oil (BSS grade; $519 \mathrm{~g}, 1.67 \mathrm{~mol})$, Grubbs'second generation catalyst $(7.0 \mathrm{~g}, 0.025 \mathrm{~m} \mathrm{~mol})$, toluene $(300 \mathrm{ml})$ were stirred mechanically under reflux at $90^{\circ} \mathrm{C}$ for $8 \mathrm{~h}$. The reaction was monitored hourly using TLC eluted with hexane: ethyl acetate $(90: 10, \mathrm{v} / \mathrm{v})$. Reaction mixture was added to a solution of tris(hydroxymethyl)-phosphine $\left(\mathrm{P}\left[\mathrm{CH}_{2} \mathrm{OH}\right]_{3}\right.$, $0.13 \mathrm{~g}, 0.0010 \mathrm{~mol})$ and triethylamine $\left(\mathrm{Et}_{3} \mathrm{~N}, 0.014 \mathrm{~mL}\right.$, $0.010 \mathrm{~g}, 1.0 \times 10-4 \mathrm{~mol})$ in DCM $(20 \mathrm{~mL})$ and stirred for $10 \mathrm{~min}$. Distilled water $(\sim 30 \mathrm{~mL})$ was then added and the biphasic solution was vigorously stirred for $>15 \mathrm{~min}$ before being allowed to separate. The aqueous layer was removed, and the organic layer was washed further with distilled water $(2 \times 30 \mathrm{~mL})$ to wash away the catalyst and passed over anhydrous sodium sulphate. The solvent was removed using rotary evaporator and dried under reduced pressure $(2-5 \mathrm{~mm} \mathrm{Hg})$ to obtain metathesized products (460 g, 95\% yield).

\subsection{Hydroxylation of metathesized castor oil}

To metathesized castor oil $(412 \mathrm{~g}, 0.764 \mathrm{~mol})$, formic acid $(85 \% ; 6.6 \mathrm{~g}, 1.14 \mathrm{~mol})$ and concentrated sulfuric acid (2\% weight of formic acid and hydrogen peroxide) were added and stirred under mechanical stirring at $5-10^{\circ} \mathrm{C}$. Hydrogen peroxide solution, $(30 \%, 2.29 \mathrm{~mol})$, were added slowly to the contents through addition funnel for a period of $2 \mathrm{~h}$ at $0{ }^{\circ} \mathrm{C}$. This precaution was taken to prevent over heating of the system due to the exothermic nature of epoxidation. After addition of the $\mathrm{H}_{2} \mathrm{O}_{2}$ the temperature was slowly raised to $60^{\circ} \mathrm{C}$ and then to $90^{\circ} \mathrm{C}$ for $24 \mathrm{~h}$. The course of the reaction was monitored by withdrawing aliquots of the reaction mixture at various time intervals and analyzing for oxirane value. After complete conversion, the reaction mixture was cooled, extracted with ethyl acetate and washed with water until acid free to obtain hydroxylated product with $93 \%$ yield. The product was analyzed for acid value, oxirane value, iodine value and hydroxyl value.

\subsection{Acylation of hydroxylated metathesized castor oil}

Hydroxylated metathesized castor oil ( $356 \mathrm{~g}, 0.8 \mathrm{~mol})$, Acetic anhydride $(130 \mathrm{~g}, 2.54 \mathrm{~mol}), \operatorname{DMAP}(0.3 \mathrm{~g}, 0.1 \%$ DMAP based on weight of hydroxylated metathesized castor oil), and xylene $(150 \mathrm{~mL})$ were taken in a three-necked roundbottom flask and stirred at $135-140^{\circ} \mathrm{C}$ for $8 \mathrm{~h}$. The progress of the reaction was monitored by TLC using hexane/ ethyl acetate $(80: 20 \mathrm{v} / \mathrm{v})$ and IR. The crude product was distilled at $140{ }^{\circ} \mathrm{C}$ and $5 \mathrm{~mm} \mathrm{Hg}$ to remove excess acetic anhydride and xylene. The residue was extracted into ethyl acetate, washed with water, passed over anhydrous sodium sulfate and concentrated using a rotary evaporator and dried under reduced pressure to obtain acetylated product. The product was further purified to remove traces of acetic acid by passage through a basic alumina column to obtain acetylated metathesized castor oil) with an acid value of $<0.2$. The product was analyzed for hydroxyl value. The structure of the product was confirmed by $I R,{ }^{1} \mathrm{H} N M R$ and ${ }^{13} \mathrm{C}$ NMR spectral studies.

Similar procedure was followed for the propionylation, butanoylation and hexanoylation of hydroxylated metathesized castor oil ( $356 \mathrm{~g}, 0.8 \mathrm{~mol}$ ), by taking propionic anhydride $(157 \mathrm{~g}, 2.42 \mathrm{~mol})$, butanoic anhydride (172 g, $2.18 \mathrm{~mol})$ and hexanoic anhydride $(221 \mathrm{~g}, 2.07 \mathrm{~mol})$ respectively. The structures of all the alkanoylated esters were confirmed by IR, ${ }^{1} \mathrm{H}$ NMR and ${ }^{13} \mathrm{C}$ NMR spectral studies. 


\section{Results and discussion}

Castor oil with composition (palmitic acid, $0.9 \%$; stearic acid, $1.2 \%$; oleic acid, $4.0 \%$; linoleic acid, $4.6 \%$; ricinoleic acid $89.3 \%$ ) was utilized to develop four homologous lubricant base stocks employing a three step procedure.

Step 1 Metathesis of castor oil

Castor oil $(0.166 \mathrm{~mol})$ was self-metathesized in the presence of Grubbs' second generation catalyst $(0.025 \mathrm{~m} \mathrm{~mol})$. The nature of the formation of metathesized products was also monitored varying the concentration of Grubbs' catalyst $0.025-0.030 \mathrm{~m} \mathrm{~mol})$. Maximum conversion was observed at $0.03 \mathrm{~m} \mathrm{~mol}$ concentration itself with about $95 \%$ yields. The presence of peaks at (m/z: 1802, 1264, 643, 599.4) in MALDI SPECTRUM indicated the formation of monomers, dimers and trimers of metathesized castor oil containing ricinoleic acid which accounts for $90 \%$ and other peaks indicate metathesized products containing ricinoleic, oleic, linoleic and saturated fatty acid containing products.

Step 2 Hydroxylation of metathesized castor fatty acids

The metathesized product mixture were hydroxylated using one pot synthesis of epoxidation followed by hydroxylation employing Prilezhaev dihydroxylation method with $93 \%$ yield. The hydroxylated products were analyzed for oxirane value, hydroxyl value, iodine value and characterized using spectral techniques. The products with low oxirane, $<3$; iodine, $\leq 1.5$ and high hydroxyl values, indicated almost complete hydroxylation of branched mono-dimeric and trimeric metathesized products. The hydroxylated metathesized product mixture was further characterized using IR, ${ }^{1} \mathrm{H}$ NMR and ${ }^{13} \mathrm{C}$ NMR Spectral analysis.

The presence of prominent $-\mathrm{OH}$ stretching band $\left(\sim 3448 \mathrm{~cm}^{-1}\right)$ as observed in IR spectra along with disappearance of $=\mathrm{C}-\mathrm{H}$ and epoxy stretching bands supported complete hydroxylation. The presence of a multiplet at $\sim 1.46$ to $1.51 \mathrm{ppm}$ relating to $-\mathrm{CH}(\mathrm{OH})-\mathrm{C}_{2}-$ and multiplet at $\sim 3.36$ to $3.45 \mathrm{ppm}$ relating to $-\mathrm{CH}-\mathrm{OH}$ in ${ }^{1} \mathrm{H}$ NMR and also characteristic peaks at 74.2,77.2 ppm relating to $C_{9}$ and $C_{10}$ hydroxyl carbons in ${ }^{13} \mathrm{C}$ NMR further confirmed hydroxylation.

Step 3 Acylation of the epoxidised products

Acylation of the hydroxylated products was carried out using acetic, propionic, butyric and hexanoic anhydrides to obtain -Acetylated metathesized castor oil (MCAC), Propanoylated metathesized castor oil (MCPR), Butanoylated metathesized castor oil (MCBT), Hexanoylated metathesized castor oil (MCHX) with 85-80\% yields ((Scheme 1). The hydroxyl value in all the cases was $\leq 2$ indicating that almost all the $-\mathrm{OH}$ groups have been acetylated (Table 1). The structure of the acetylated products was further confirmed by ${ }^{1}$ HNMR and IR spectral studies.

IR spectra shows stretching band at $1735 \mathrm{~cm}^{-1}$ (MCAC); $1740 \mathrm{~cm}^{-1}$ (MCPR), $1736 \mathrm{~cm}^{-1}$ (MCBT), and $1734 \mathrm{~cm}^{-1}$ (MCHX) related to acylated side chain. In the case of ${ }^{1} \mathrm{H}$ NMR spectra appearance of new peaks at around $\delta 4.15(\mathrm{~m}$, $\left.-\mathrm{C}_{2}-\mathrm{O}-\mathrm{CO}-\mathrm{CH}_{2}-\right), 4.88\left(\mathrm{~m},-\mathrm{C} \underline{\mathrm{H}}-\mathrm{O}-\mathrm{CO}-\mathrm{CH}_{2}-\right), 5.42(\mathrm{~m}$, $-\mathrm{C} \underline{\mathrm{H}}=\mathrm{C} \underline{\mathrm{H}}-)-\mathrm{MCAC} ; 4.15\left(\mathrm{~m},-\mathrm{C}-\mathrm{C}_{2}-\mathrm{O}-\mathrm{CO}-\mathrm{CH}_{2}-\right), 4.9(\mathrm{~m}$, $-\mathrm{C}$ - $\left.-\mathrm{O}-\mathrm{CO}-\mathrm{CH}_{2}-\right)$, MCPR; $4.86\left(\mathrm{~m},-\mathrm{CH}-\mathrm{O}-\mathrm{CO}-\mathrm{CH}_{2}-\right), 5.42$ $\left(\mathrm{m},-\mathrm{CH}_{2}-\mathrm{C}-(\mathrm{O}-\mathrm{C}=\mathrm{O})-\mathrm{CH}_{2}-\right)-\mathrm{MCBT} ; 4.14\left(\mathrm{~m},-\mathrm{C}-\mathrm{CH}_{2}-\mathrm{O}-\mathrm{CO}-\mathrm{CH}_{2}-\right)$, $4.86\left(\mathrm{~m},-\mathrm{C} \underline{\mathrm{H}}-\mathrm{O}-\mathrm{CO}-\mathrm{CH}_{2}-\right), 5.44(\mathrm{~m},-\mathrm{C} \underline{\mathrm{H}}=\mathrm{C} \underline{\mathrm{H}}-)-\mathrm{MCHX}$ indicated the ester formation. In ${ }^{13} \mathrm{C}$ NMR spectra the peaks at around $\delta 76.6 \mathrm{ppm}-\mathrm{MCAC} ; \delta 77.6 \mathrm{ppm}-\mathrm{MCPR} ; \delta 76.3 \mathrm{ppm}-$ MCBT; $\delta 76.3$ ppm-MCHX related to $-\mathrm{CH}_{2}-\mathrm{CH}-\mathrm{O}-\mathrm{C}(\mathrm{O})-\mathrm{R}$, around 173.9 ppm-MCAC; 174.2 ppm-MCPR; 173.6 ppmMCBT; 173.1 ppm-MCHX related to acylated carbon, indicated the acylation of hydroxylated castor metathesized products.

\subsection{Lubricant and tribological properties}

The castor oil and their metathesized acylated products were evaluated for lubricant properties (Table 1). The densities of the acetylated products were quite high and were found to increase with increase in the branching chain length, i.e. acetylated to hexanoylated. Similarly the viscosities of these compounds also increased from acylated to hexanoylated derivatives, $45.5 \mathrm{cSt}$ to $60.1 \mathrm{cSt}$. The increase in viscosities with chain lengths was also observed in several acylated derivatives of earlier studies [32-34]. The viscosity indices, which are indicative of change in viscosity with change in temperature were also high, a highly desirable property for lubricants. In general vegetable oils have viscosity indices around 200 , while petroleum based oils have $\mathrm{VI} \leq 100$. Hence, these highly branched metathesized castor acylated products can be used without any viscosity improvers unlike mineral oil based [35]. These products have viscosity indices in the range 170-190, useful for a number of hydraulic and metal working fluid applications [36].

Another important property by this modification is low cold flow properties as measured by their pour points. The pour points of these products were very low and decreased further from -30 to $-40^{\circ} \mathrm{C}$. Low pour points are very much desirous for almost all the applications, ranging from hydraulic fluids to aviation and turbine 


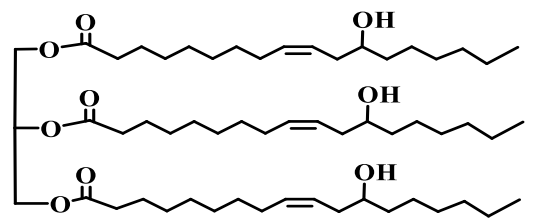

Castor oil ( Ricinolic acid $87-90 \%$ )

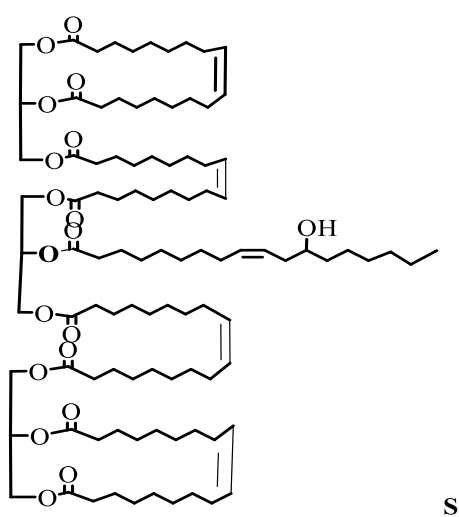

G-II catalyst, $\mid$ toluene, $90^{\circ} \mathrm{C}, 8 \mathrm{hr}$<smiles>CCCCCCCCCCCCC(=O)OCCOC(=O)OC</smiles>

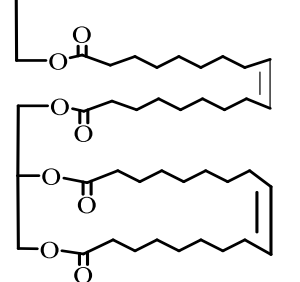

Self-metathesis of castor oil

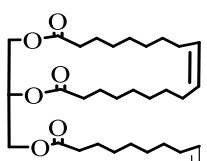

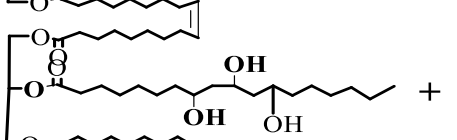

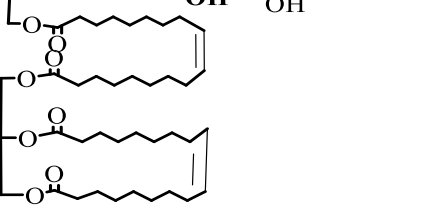

Metathesized hydroxylated castor oil derivatives

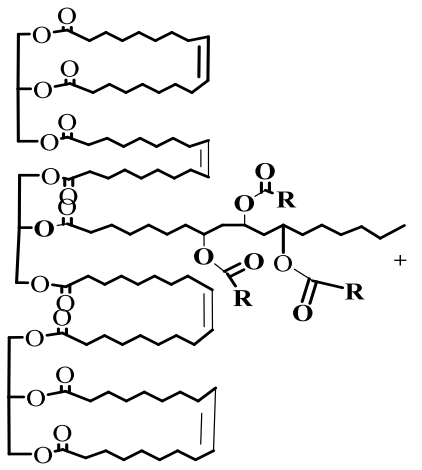

$+$

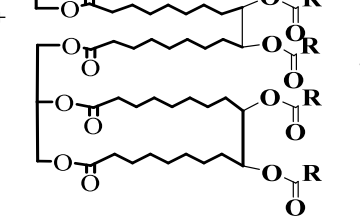

$\mathbf{R}=$ methyl,ethyl,propyl,pentyl

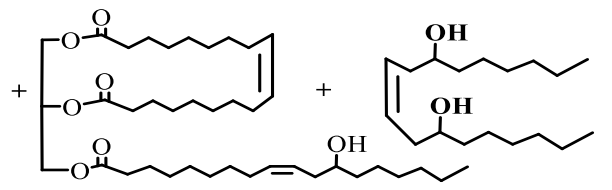

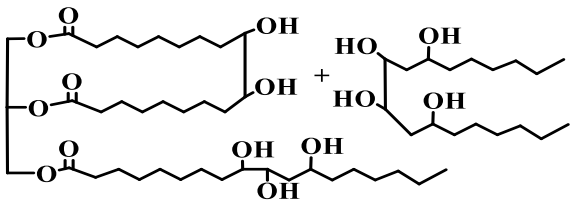

Metathesized castor acylated derivatives

Scheme 1 Synthesis of metathesized castor acylated derivatives

lubricants [36]. These low temperatures can be attributed to the highly branching structures, disrupting the micro crystaline structures [22]. In general base stocks derived from vegetable oils cannot remain liquid in cold storage for more than 1 day; therefore addition of PPD becomes essential. However, in the present study use of PPD can be avoided during formulations. The values were found to be quite low compared to any other high viscosity polyol derivatives $[7,18,32]$.

Flash point indicates the lubricant volatility, fire resistance and transportation and storage temperature requirements. In general flash point of the lubricants should be high for safe operation especially at high temperatures. The castor metathesized acylated products have very high 
Table 1 Physico-chemical and Lubricant Properties of MCAC, MCPR, MCBT, MCHX

\begin{tabular}{|c|c|c|c|c|c|c|}
\hline Test & Method & Castor oil & MCAC & MCPR & MCBT & $\mathrm{MCHX}$ \\
\hline Total acid number & AOCS Te 2a-64 & 0.869 & 0.200 & 0.051 & 0.014 & 0.031 \\
\hline Hydroxyl value & AOCS Cd 13-60 & 167 & 1.1 & 1.3 & 1.9 & 1.8 \\
\hline Density at $15^{\circ} \mathrm{C}\left(\mathrm{g} / \mathrm{cm}^{3}\right)$ & ASTM D 4052 & 0.9621 & 0.9540 & 0.9510 & 0.9458 & 0.0975 \\
\hline Specific gravity at $15^{\circ} \mathrm{C}$ & ASTM D 4052 & 0.9587 & 0.9549 & 0.9569 & 0.9467 & 0.9541 \\
\hline \multicolumn{7}{|l|}{ Kinematic viscosity (cSt) } \\
\hline $40^{\circ} \mathrm{C}$ & ASTM D 445 & 231.22 & 45.5 & 51.5 & 55.0 & 60.1 \\
\hline $100^{\circ} \mathrm{C}$ & & & 7.81 & 9.78 & 9.80 & 9.85 \\
\hline Viscosity index (VI) & ASTM D 2270 & & 170 & 182 & 185 & 190 \\
\hline Pour point $\left({ }^{\circ} \mathrm{C}\right)$ & ASTM D 97 & 2.7 & -30 & -32 & -36 & -40 \\
\hline Flash point $\left({ }^{\circ} \mathrm{C}\right)$ & ASTM D 93 & 228 & 165 & 172 & 179 & 191 \\
\hline TGA onset temperature $\left({ }^{\circ} \mathrm{C}\right)$ & - & - & 349 & 358 & 370 & 373 \\
\hline Copper corrosion & ASTM D 130 & 1a (slightly tarnish) & $1 \mathrm{a}$ & $1 \mathrm{a}$ & $1 \mathrm{a}$ & $1 \mathrm{a}$ \\
\hline Oxidative stability (min) (RPVOT) & ASTM D 2272 & 12 & 20 & 20 & 18 & 14 \\
\hline Oxidative stability with BHT (0.5\%) & & - & 30 & 30 & 25 & 20 \\
\hline Weld load (Kg) & IP 239 & 120 & 165 & 170 & 180 & 184 \\
\hline Wear $(\mathrm{mm})$ & ASTM D 4172 & 1.0894 & 0.5210 & 0.5788 & 0.6701 & 0.6908 \\
\hline
\end{tabular}

MCAC-Acetylated Metathesized Castor Oil, MCPR-Propanoylated Metathesized Castor Oil, MCBT-Butanoylated Metathesized Castor Oil, MCHX-Hexanoylated Metathesized Castor Oil; The analysis were carried out in triplicates and the reported values are an average of the triplicate results

flash points $165-191^{\circ} \mathrm{C}$ much suitable for hydraulic, metal working, forging and aviation applications [15].

The metathesized castor acylated products when evaluated for wear-scar diameter exhibited extraordinary values (WSD, MCAC, 0.52 mm; MCPR, $0.57 \mathrm{~mm}$; MCBT, $0.67 \mathrm{~mm}$; $\mathrm{MCHX}, 0.69 \mathrm{~mm})$, much reduced values compared to other polyol and castor acylated products [18, 19, 36-38]. This may be attributed to the fact that high molecular weight metathesized castor acylated products form a thick film over the steel surface thereby increasing lubricity and the reduction in wearing. This property increased with increase in chain length of the acylated moiety. The extreme pressure (EP) performance of these products was also found to be excellent ranging from 165 to $184 \mathrm{~kg}$ and was found to increase with increase in the chain length branching. This can be explained that the increase in chain length of the metathesized castor acylated products, generates a thick protective film thereby preventing the development of friction [33]. Hence, metathesized castor acylated products developed employing self-metathesis, followed by acylation resulted in products with excellent tribological properties, whereby, the lubricant can be used without any EP additives (Table 1).
Fig. 1 Oxidation stability of the base stocks with and without $\mathrm{BHT}$

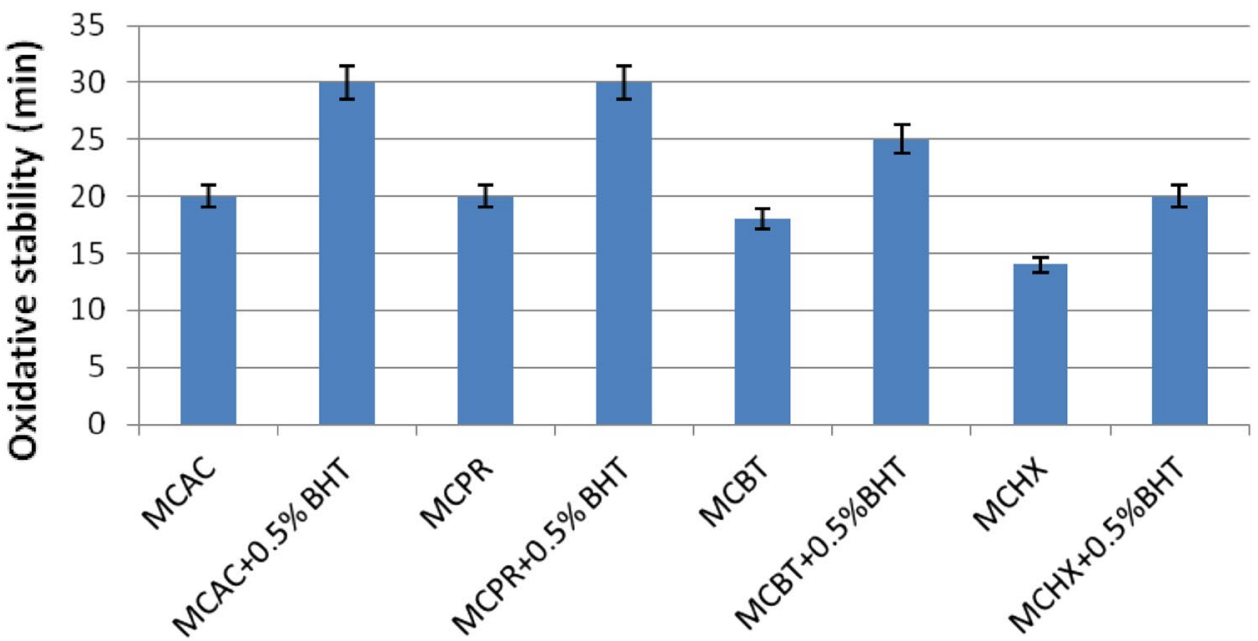

Lubricant base stock with and without BHT 
Though there are reports on chemical modification of vegetable oils in particular castor oil [39-42], the present study focuses on the development of an ideal biolubricant base stock with high viscosity index, low pour points and superior anti-wear properties which can be achieved via the metathesis route.

Vegetable oils have the drawbacks of poor oxidation stability, hence have to be modified or should be used along with antioxidant additives. In the present study, the said chemical modification of castor oil resulted in products with good oxidative stabilities 14-20 min compared to other modified castor oil products [43] (Fig. 1). It was observed that on further addition of BHT, about $0.5 \%$ (wt\% of base stock) their stabilities further increased, from 20 to $30 \mathrm{~min}$. These excellent antioxidant properties make the products desirable for use in hydraulic, metal working and aviation lubricant formulations. The products also exhibited extraordinary thermal stabilities ranging from 349 to $373^{\circ} \mathrm{C}$ (Fig. 1). It was also observed that the overall properties of castor oil (Table 1) were inferior compared to the metathesized alkanoylated esters for its application as a lubricant. The said esters with the above properties can be used in high temperature applications such as forging, aviation, hydraulic and metal working fluid applications [44].

\section{Conclusions}

The present study involved development of acylated derivatives of castor oil metathesized products with an intention to develop lubricant base stocks with high viscosity indices, low pour points and superior anti-wear properties. None of the modifications reported in literature has shown the development of base stocks with ideal lubricant properties, which could be achieved adopting metathesis route. Castor oil was self-metathesized followed by epoxidation, in situ hydroxylation and acylation to obtain metathesized acylated products in $85-90 \%$ yields. The products at all three steps were thoroughly characterized using chromatographic and spectral studies. These when evaluated exhibited high viscosities $45.5 \mathrm{cSt}$ to $60.0 \mathrm{cSt}$, sufficiently good in protecting the surface from friction, low pour points $\left(-30\right.$ to $\left.-40{ }^{\circ} \mathrm{C}\right)$ and low wear $(0.52-0.69 \mathrm{~mm})$ values due to high molecular weight and branching. The base stocks also exhibited very high flash points $165-191{ }^{\circ} \mathrm{C}$ and good load carrying capacities (165-184 kg) indicating their potential into hydraulic, metal working, forging, aviation and high temperature applications. These base stocks can be used with the use of minimum additives for the above applications.
Acknowledgements This work was carried with the financial grant given by CSIR and was supported by AcSIR-IICT, India. The authors thank DKIM (Department of Knowledge and Information Management) of CSIR-IICT for conducting plagiarism check for the manuscript. IICT Communication Number: IICT/Pubs./2019/068.

\section{Compliance with ethical standards}

Conflict of interest On behalf of all authors, the corresponding author states that there is no conflict of interest.

\section{References}

1. Horner D (2002) Recent trends in environmental friendly lubricants. J Synth Lubr 18:327-334. https://doi.org/10.1002/ jsl.3000180407

2. Rudnick LR (2006) Synthetics, mineral oils and bio-based lubricants, 2nd edn. CRC Taylor and Francis, Boca Raton, pp 353-360

3. Salimona J, Saliha N, Yousifb E (2012) Improvement of pour point and oxidative stability of synthetic ester base stocks for biolubricant applications. Arab J Chem 5:193-200. https://doi. org/10.1016/j.arabjc.2010.09.001

4. Erhan SZ, Adhvaryu A, Perez JM (2002) Vegetable oil based basestocks. Biobased Industrial Fluids and Lubricants. AOCS Press, Champaign, pp 1-19

5. Salunkhe DK, Chavan JK, Adsulke RN, Kadam SS (1992) World oil seeds: chemistry technology and utilization. Van Nostrand Reinhold, New York, pp 1-8

6. Krzan B, Vizintin J (2003) Tribological properties of environmentally adapted universal tractor transmission oil based on vegetable oil. Tribol Int 36:827-833. https://doi.org/10.1016/ S0301-679X(03)00100-2

7. Hwang HS, Erhan SZ (2001) Modification of epoxidized soybean oil for lubricant formulations with improved oxidative stability and low pour point. J Am Oil Chem Soc 78:1179-1184. https://doi.org/10.1007/s11745-001-0410-0

8. Lathi PS, Mattiasson B (2007) Green approach for the preparation of biodegradable lubricant base stock from epoxidized vegetable oil. Appl Catal B 69:207-212. https://doi. org/10.1016/j.apcatb.2006.06.016

9. Salimon J, Salih N, Yousif E (2011) Chemically modified biolubricant basestocks from epoxidized oleic acid: improved low temperature properties and oxidative stability. J Saudi Chem Soc 15:195-201. https://doi.org/10.1016/j.jscs.2010.08.004

10. Aziz NAM, Yunus R, Rashid U, Syam AM (2014) Application of response surface methodology (RSM) for optimizing the palm-based pentaerythritol ester synthesis. Ind Crops Prod 62:305-312. https://doi.org/10.1016/j.indcrop.2014.08.040

11. Erhan SZ, Sharma BK, Perez JM (2006) Oxidation and low temperature stability of vegetable oil-based lubricants. Ind Crops Prod 24:292-299. https://doi.org/10.1016/j.indcrop.2006.06.008

12. Zulkifli NWM, Kalam MA, Masjuki HH, Yunus R (2013) Experimental analysis of tribological properties of biolubricant with nanoparticle additive. Procedia Eng 68:152-157. https://doi. org/10.1016/j.proeng.2013.12.161

13. Mathiesen T (1998) Modified TMP esters as multifunctional additives in metalworking fluids. J Synth Lubr 14:381-390. https://doi.org/10.1002/jsl.3000140405

14. Zulkifli NWM, Kalam MA, Masjuki HH, Shahabuddin M, Yunus $R$ (2013) Wear prevention characteristics of a palm oil-based TMP 
(trimethylolpropane) ester as an engine. Lubr Energy 54:167173. https://doi.org/10.1016/j.energy.2013.01.038

15. Schneider A, Brenner J, Tomastik C, Franek F (2010) Capacity of selected ionic liquids as alternative EP/AW additive. Lubr Sci 22:215-223. https://doi.org/10.1002/ls.120

16. Yokogawa $M$ (2012) Manufacturing method and manufacturing system for product. US 20120016506 A1

17. Kamalakar K, Amit KR, Prasad RBN, Karuna MSL (2013) Rubber seed oil-based biolubricant base stocks: a potential source for hydraulic oils. Ind Crops Prod 51:249-257. https://doi. org/10.1016/j.indcrop.2013.08.058

18. Kamalakar K, Mohini Y, Rao BVSK, Karuna MSL, Prasad RBN (2013) Sal fatty acid-based biolubricant base-stocks: a potential source for high temperature applications. J Lipid Sci Technol 45:79-85

19. Sammaiah A, Padmaja KV, Prasad RBN (2014) Synthesis and evaluation of novel acyl derivatives from jatropha oil as potential lubricant basestocks. J Agric Food Chem 62:4652-4660. https ://doi.org/10.1021/jf501388d

20. Kockritz A, Martin A (2011) Synthesis of azelaic acid from vegetable oil-based feedstocks. Eur J Lipid Sci Technol 113:83-91. https://doi.org/10.1002/ejlt.201000117

21. Martin A, Richter M (2011) Oligomerization of glycerol-a critical review. Eur J Lipid Sci Technol 113:100-117. https://doi. org/10.1002/ejlt.201000386

22. Mutlu H, Meier MAR (2010) Castor oil as renewable resource for chemical industry. Eur J Lipid Sci Technol 112:10-30. https://doi. org/10.1002/ejlt.200900138

23. Salimon J, Salih N (2006) Modification of epoxidized ricinoleic acid for biolubricant base oil with improved flash and pour points. Asian J Chem 22:5468-5476

24. Yanishlieva N, Marinova E, Pokorny J (2006) Natural antioxidants from herbs and spices. Eur J Lipid Sci Technol 108:776-793. https ://doi.org/10.1002/ejlt.200600127

25. Basiron $Y$ (2007) Palm oil production through sustainable plantations. Eur J Lipid Sci Technol 109:289-295. https://doi. org/10.1002/ejlt.200600223

26. Carlsson AS, Lindberg-Yilmaz J, Green AG, Stymne S, Hofvander P (2011) Replacing fossil oil with fresh oil-with what and for what? Eur J Lipid Sci Technol 113:812-831. https://doi. org/10.1002/ejlt.201100032

27. Carter C, Finley W, Fry J, Jackson D, Willis L (2007) Palm oil markets and future supply. Eur J Lipid Sci Technol 109:307-314. https://doi.org/10.1002/ejlt.200600256

28. Fajardo AR, Cerdan LE, Medina AR, Fernandez FGA (2007) Lipid extraction from the microalga Phaeodactylum tricornutum. Eur J Lipid Sci Technol 109:120-126. https://doi.org/10.1002/ ejlt.200600216

29. Padmaja KV, Rao BVSK, Reddy RK, Bhaskar PS, Singh AK, Prasad RBN (2012) 10-Undecenoic acid-based polyol esters as potential lubricant base stocks. Ind Crops Prod 35:237-240. https://doi. org/10.1016/j.indcrop.2011.07.005

30. Noureddini H, Teoh BC, Clements LD (1992) Viscosities of vegetable oils and fatty acids. J Am Oil Chem Soc 69:1 189-1191. https ://doi.org/10.1007/BF02637678

31. Sammaiah A, Padmaja KV, Kaki SS, Prasad RBN (2015) Multifunctional lubricant additives derived from natural amino acids and methyl oleate. RSC Adv 5:77538-775441. https://doi. org/10.1039/C5RA15239A

32. AOCS (1997) Oxirane oxygen in epoxidized materials. In: Official methods and recommended practices of the AOCS, 5 th edn. $\mathrm{Cd}$ 9-57

33. de Vasconcelos R, Lopes V, Zamian JR, Resck IS, Jose M, Sales A, Lucilia M, dos Santos F, da Cunha R (2010) Physicochemical and rheological properties of passion fruit oil and its polyol. Eur J Lipid Sci Technol 112:1253-1262. https://doi.org/10.1002/ ejlt.201000098

34. Valeri D, Meirelles AJA (1997) Viscosities of fatty acids, triglycerides, and their binary mixtures. J Am Oil Chem Soc 74:12211226. https://doi.org/10.1007/s11746-997-0048-6

35. Gorla G, Kour SM, Padmaja KV, Karuna MSL, Prasad RBN (2013) Preparation and properties of lubricant base stocks from epoxidized karanja oil and its alkyl esters. Ind Eng Chem Res 52:16598-16605. https://doi.org/10.1021/ie4024325

36. Schneider MP (2006) Plant-oil-based lubricants and hydraulic fluids. J Sci Food Agric 86:1769-1780. https://doi.org/10.1002/ jsfa.2559

37. Masjuki HH, Maleque MA, Kubo A, Nanoka T (1999) Palm oil and mineral oil based lubricants-their tribological and emission performance. Tribol Int 32:305-314. https://doi.org/10.1016/S0301 $-679 \times(99) 00052-3$

38. Havet L, Blouet J, Velloire FR, Brasseur E, Slomka D (2001) Tribological characteristics of some environmentally friendly lubricants. Wear 248:140-146. https://doi.org/10.1016/S0043 -1648(00)00550-0

39. Kamalakar K, Mahesh G, Prasad RBN, Karuna MSL (2015) A novel methodology for the synthesis of acyloxy castor polyol esters: low pour point lubricant basestocks. J Oleo Sci 64:1283-1295. https://doi.org/10.5650/jos.ess15133

40. Rao BVSK, Padmaja KV, Karunakar Reddy R, Bhaskar PS, Saravanan K, Prasad RBN (2017) 9,10,12-Tricycloxy acetadecanoic acid alkyl esters as potential lubricant back stocks. Indian Patent No. 288753

41. Bhaskar PS, Padmaja KV, Rao BVSK, Saravanan K, Prasad RBN (2017) Castor oil fatty acid based estolide esters and their acetates as potential lubricant base stocks, Indian Patent No. 281351

42. Padmaja KV, Rao BVSK, Bhaskar PS, Prasad RBN, Singh AK, (2016) Polyol esters of undecenoic and undecanoic acids as potential lubricant base stocks. Indian Patent No. 278776

43. American Society for Testing and Material (ASTM D 2272-11) (2002) Standard test method for oxidation stability of steam turbine oils by rotating pressure vessel. ASTM Book of Standards; ASTM, West Conshohocken

44. Sharma BK, Liu Z, Adhvaryu A, Erhan SZ (2008) One-pot synthesis of chemically modified vegetable oils. J Agric Food Chem 56:3049-3056. https://doi.org/10.1021/jf073070z

Publisher's Note Springer Nature remains neutral with regard to jurisdictional claims in published maps and institutional affiliations. 